\title{
(Self-) Enforcement of Joint Implementation and Clean Development Mechanism Contracts
}

\author{
Josef JANSSEN * \\ January 1999
}

Institute for Economy and the Environment at the University of St. Gallen (IWO-HSG), Switzerland

and

Fondazione ENI Enrico Mattei (FEEM), Milan, Italy

paper presented at the

First World Congress of Environmental and Resource Economists

June 1998, Venice

\section{Address for correspondence:}

Tigerbergstrasse 2

CH-9000 St. Gallen

Switzerland

E-mail: JOSEF.JANSSEN@UNISG.CH

Phone: $+41-71-2242583$

Fax: $+41-71-2242722$

Acknowledgements: Ernst Mohr (University of St. Gallen, Institute for Economy and the Environment, Switzerland), Bernd Genser and Carsten Schmidt (both University of Konstanz, Faculty of Economics and Statistics, Germany) for valuable comments and discussions. Deutsche Forschungsgemeinschaft DFG for financial support. 


\section{Su m mary}

International climate protection investments (Joint Implementation and Clean Development Mechanism projects) are burdened with problems of contract enforcement, which prevent the realisation of efficiency gains associated with these investments. The paper analyses this problem from the perspective of non-cooperative game theory and proposes two different solutions to the cooperation problem. The first analyses the potential role of national environmental authorities in facilitating credible commitment of the project host operating under its jurisdiction. It is argued that the threat of punishing the project host if he breaches the contract may serve this purpose. The effective level of punishment is derived. The second option involves strategic delegation of contract implementation to a third party operating under the same jurisdiction as the project host. Again, the paper explores the conditions that ensure incentive-compatibility. Both options are based on the idea that the project sponsor may commit himself credibly by becoming a Stackelberg leader.

\section{Keywords}

Joint Implementation, Clean Development Mechanism, climate protection, international environmental agreements, international investments, contract enforcement, cooperation, incentive compatibility

\section{JEL Classification}

D21, D62, D70, F20, F23, K12, K40, Q25, Q28, Q40 


\section{Non-Technical Summary}

The Kyoto Protocol on climate change stipulates that industrialised countries and countries with economies in transition ("Annex I Parties") shall reduce their overall emissions of six greenhouse gases by at least 5 per cent below 1990 levels in the first commitment period 2008 to 2012. In order to fulfil these commitments in a cost-efficient way, Annex I countries may use the Kyoto mechanisms "Joint Implementation" (JI), "Clean Development Mechanism" (CDM), and "International Emissions Trading" (IET).

The basic idea of the Kyoto mechanisms refers to the possibility of producing abroad (JI or CDM) and/or importing (IET) the emission reductions necessary to meet the emission reduction or limitation targets of individual countries, sectors or firms. This possibility enhances overall efficiency since differentials in abatement cost between countries, sectors and greenhouse gas emitting companies are exploited.

A fundamental problem associated with the effectiveness and stability of international JI/CDM contracts arises from the fact that international contracts are difficult to enforce because they are made between entities that fall under the jurisdiction of distinct sovereign states. This paper investigates strategies to cope with this problem from a game theoretic perspective.

The first section gives a brief idea of the Kyoto Mechanisms. The second section analyses the fundamental problem of international JI/CDM contracts by modelling them as a non-cooperative, simultaneous one-shot game. The two players represent a JI/CDM project sponsor and the foreign project host that implements the JI/CDM project, respectively. It is shown that without any specific provisions against breach of contract, both JI/CDM contract parties will renege on their respective contractual obligations by behaving non-cooperatively. Consequently, the JI/ CDM project will not be realised and the associated efficiency gains are not seized.

The third section analyses how to design institutions and strategies that credibly commit both JI/CDM contract parties to meet their contractual obligations by behaving cooperatively. One option for stabilising the JI/CDM contract focuses on the potential role of national environmental authorities. It is explored if they could provide a mechanism by which potential JI/CDM project sponsors could credibly commit to cooperative behaviour. 
It is argued that national environmental authorities indeed may serve this function by penalising breaches of JI/CDM contracts on the part of the contract party belonging to its jurisdiction. The paper derives the minimal required level of the penalty.

Another option involves sequential moving on the one hand, and on the other hand strategic delegation of contract fulfilment to an agent who plays the JI/CDM game on behalf of the project host. The delegation arrangement is fixed by a binding contract between the principal, i.e. the JI/CDM project host, and an agent. The paper derives conditions that allow the implementation of the cooperative solution of the modified JI/CDM game. These conditions refer to the incentive-compatible payment to the agent. 


\section{Contents}

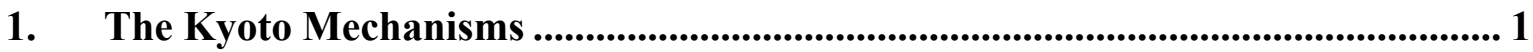

2. Country Sovereignty as Reason for Unstable JI and CDM Contracts ................. 4

3. Institutions and Strategies for Stabilising JI and CDM Contracts ......................9

3.1 Commitment of the Sponsor by Advanced Payment...................................... 10

3.2 Commitment Strategies of the Project Host .................................................. 11

3.2.1 Punishment of Breaches of Contract by the

National Environmental Authority ….................................................. 11

3.2.2 Self-Commitment of the Project Host through

Strategic Delegation .................................................................. 14

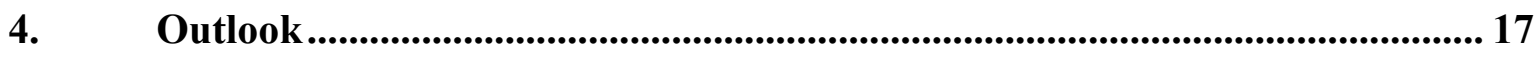

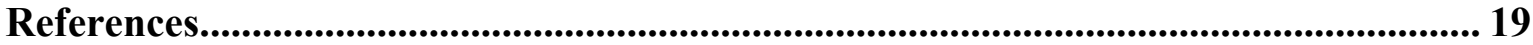


In conclusion, while ... enforcement mechanisms will play a key role in JI under the FCCC, careful reporting and inspection systems seem for the time being to be the maximum achievable.

[SCHRIJVER (1995), S. 140]

\section{The Kyoto Mechanisms}

The Kyoto Protocol, adopted in December '97, provides that industrialised countries and countries with economies in transition ("Annex I Parties") shall reduce their overall emissions of six greenhouse gases by at least 5 per cent below 1990 levels in the first commitment period 2008 to 2012. In order to fulfil these commitments in a costefficient way, Annex I countries may use the Kyoto mechanisms "Joint Implementation" (JI), "Clean Development Mechanism" (CDM), and "International Emissions Trading" (IET).

The basic idea of these instruments refers to the possibility of producing abroad and/or importing the emission credits needed to meet the emission commitment of individual countries, sectors and companies. Since mitigation of global warming is independent from the spatial distribution of greenhouse gas emission abatement efforts, the overall environmental effectiveness is not reduced by this internationalisation of abatement activities. However, since abatement costs differ significantly across countries, sectors, firms and plants, the use of the Kyoto mechanisms may lead to huge cost savings or profit opportunities at firm level, and corresponding welfare gains at the aggregate national and international level.

JI projects are international projects ,aimed at reducing anthropogenic emissions by sources or enhancing anthropogenic removals by sinks of greenhouse gases in any sector of the economy“ (article 6). Both, the sponsor country and the host country are required to belong to the group of Annex I Parties. JI projects may be realised by legal entities operating under the jurisdiction of Annex I Parties. 
In substance, CDM projects are very similar to JI projects. Again, private entities may participate in CDM projects. The main difference between JI and CDM refers to the requirement that host countries of CDM projects shall be members of the group of nonAnnex I Parties (i.e. developing countries). Another important difference relates to the fact that, in contrast to JI, forest projects are not (yet) explicitly eligible for CDM projects.

IET refers to the acquisition and the transfer of emission credits or permits between countries with legally binding and quantified emission limitation or reduction objectives (essentially the group of Annex-I-Parties). The Kyoto Protocol does not explicitly mention the participation of the private sector. However, it is implicitly assumed that IET should be designed especially for private sector participation. In this case, distinct companies that have quantitative emission targets may transfer and acquire emission permits, which previously have been allocated or devolved to them by respective national authorities. A firm that over-complies may transfer permits to another company that uses these transferred permits to get into compliance.

A convincing distinction between JI and IET is not so easy to make. Both forms refer to international cooperation between countries with legally binding emission reduction or limitation targets. Several distinctions have been proposed. Some proposals consider JI as being an imperfect substitute for IET, which might lead to the conclusion that the importance of JI will diminish and eventually disappear as IET develops. A more convincing distinction, which will be used in this paper, is the following: JI simply refers to the international production of emission credits involving international investments, whereas IET represents international trade in emission credits. In this interpretation, JI and IET are rather complementary to each other than JI being an imperfect substitute for IET: The emission credits produced abroad by means of JI may be marketed internationally via IET, thus enhancing the liquidity of the market. Hence, the various proposals for establishing organised markets for IET will rather promote than jeopardise the development of a viable JI (and CDM) regime.

Several questions related to the practical implementation of the Kyoto mechanisms are presently discussed in the political and academic debate. ${ }^{1}$ The list of unresolved problems on the political agenda seems endless. Amongst the more important

\footnotetext{
${ }^{1}$ See e.g. Goldemberg (ed.) (1998), Matsuo (1998), or Missfeldt (1998). The political agenda regarding the elaboration of rules and guidelines for the Kyoto Mechanisms, which is part of the so-called Buenos Aires action plan, is contained in UNFCCC (1998).
} 
ones, they include the determination of the amount of additional emission reductions, i.e. emission credits, obtained by JI or CDM projects (,baseline issue“, „environmental additionality“), and the design of efficient and effective compliance mechanisms. ${ }^{2}$

The design of appropriate enforcement mechanisms for JI and CDM contracts has rather been neglected in the political and academic debate. This is surprising, since JI and $\mathrm{CDM}$ projects are especially burdened with enforcement problems that arise due to the fact that international contracts are made between entities that fall under the jurisdiction of distinct sovereign states. This problem is aggravated by the fact that JI/CDM contracts involve an inherent long-term relationship between the contract partners. The purpose of this paper is to analyse the problem of enforcing JI and CDM contracts, and to discuss possible solutions, based on a game-theoretic approach. ${ }^{3}$

The next section describes the problem of enforcing JI and CDM contracts putting it into a game-theoretic framework. Since international contracts de facto are rather nonbinding due to the involvement of sovereign countries, a non-cooperative approach is used.

In the third section two different mechanisms for removing inherent enforcement problems are discussed. Both proposals are based on the idea that at least one party of a JI/CDM contract can credibly commit himself to fulfil his contract obligations by moving first. Doing so, however he expects the other party to meet his contract obligations, too. The paper discusses two different mechanisms that indeed would enable a credible commitment by the second party. Firstly, a sanction mechanism at the national level is proposed. Secondly, strategic delegation of contract fulfilment may provide a credible selfcommitment strategy.

\footnotetext{
${ }^{2}$ Regarding compliance mechanisms for an international climate treaty see e.g. Heister et al. (1997).

${ }^{3}$ The problem of enforcing international contracts involving sovereign countries has attracted much attention in economics. Eaton and Fernandez (1995) or Mohr (1991a) analyse international debt relations. Staiger (1995) focuses on international trade. Thomas and Worrall (1994) explore international direct investments. International environmental agreements are examined e.g. by Barrett (1994), Carraro and Siniscalco (1993), Mohr (1995) and (1991b), or Mohr and Thomas (1998). Schmidt (1998) provides a survey of the latter research field.
} 


\section{Country Sovereignty as Reason for Unstable JI and CDM Contracts}

JI/CDM projects are economically viable if marginal abatement costs of the JI/CDM projects considered are lower than those of alternative projects in the sponsor country are. The realisation of these cost differentials leads to efficiency gains, or economic surplus, associated with JI/CDM projects, and is the main rational for engaging in JI/CDM activities. If such efficiency gains are realised, both the project sponsor and the project host will benefit: The project sponsor will benefit because he is able to meet a given emission reduction obligation at lower costs. The project host will benefit by sharing in the economic surplus generated by the exploitation of existing cost differentials. ${ }^{4}$ Due to liberty to make a contract, the existence of such benefits on both sides is a precondition for entering into JI/CDM contracts. In game-theoretic terms, the participation or individual rationality constraints have to be fulfilled.

Entering into the contract does not automatically lead to its implementation. For the actual implementation of the JI/CDM project it is decisive that the obligations assumed are de facto binding and enforceable. However, international contracts, as compared to national contracts, are in general difficult to enforce by compulsion due to sovereignty of states. In principle, this fact applies also to international JI/CDM contracts.

For this reason, the design of JI/CDM contracts should not only ensure that both parties might benefit from the project. Furthermore, the contract should be designed in such a way that both parties do have permanent incentives to abide voluntarily by the contract. In this case, the contract is self-enforcing. In game-theoretic terms, the incentive compatibility constraints of the JI/CDM contract should be fulfilled. The consideration of the incentive compatibility constraints of JI/CDM contracts is essential for the actual performance of JI/CDM projects, and the development of stable JI/CDM regimes. Surprisingly, it has attracted only minor attention in the present debate.

\footnotetext{
${ }^{4}$ The concrete sharing scheme will depend on the structure of the JI/CDM project market and the bargaining power of the parties [Mohr (1996), Siniscalco, Goria and Janssen (1998)]. The project host may also benefit from secondary effects like technology transfer or improvement of local or national environmental conditions.
} 
The basic structure of the problem may be analysed by the following simple game between the JI/CDM investor and the JI/CDM host. Due to observed prevalence of nonenforceable international contracts, this game is non-cooperative by definition. For analytical motives it is assumed for the time being that both parties decide simultaneously and in a one-shot manner about keeping to, or breaking of the contract. Furthermore, complete information is assumed.

The index $S(H)$ denotes the sponsor (the host). Both players can choose between two actions or strategies. ${ }^{5}$ On the one hand they can behave cooperatively abiding by the terms of the contract: The investor makes available the funds required as stipulated by the contract $\left(C^{S}\right) .{ }^{6}$ The host adopts the measures as stipulated by the contract $\left(C^{H}\right)$. Since the contract de facto is non-binding, both parties have the possibility to breach the contract: The investor could refuse the payment of the agreed funds $\left(D^{S}\right)$, whereas the host could refrain from adopting the measures required producing the emission credits $\left(D^{H}\right)$.

The following matrix may represent this non-cooperative, simultaneous one-shot JI/CDM game:

\section{Project Sponsor}

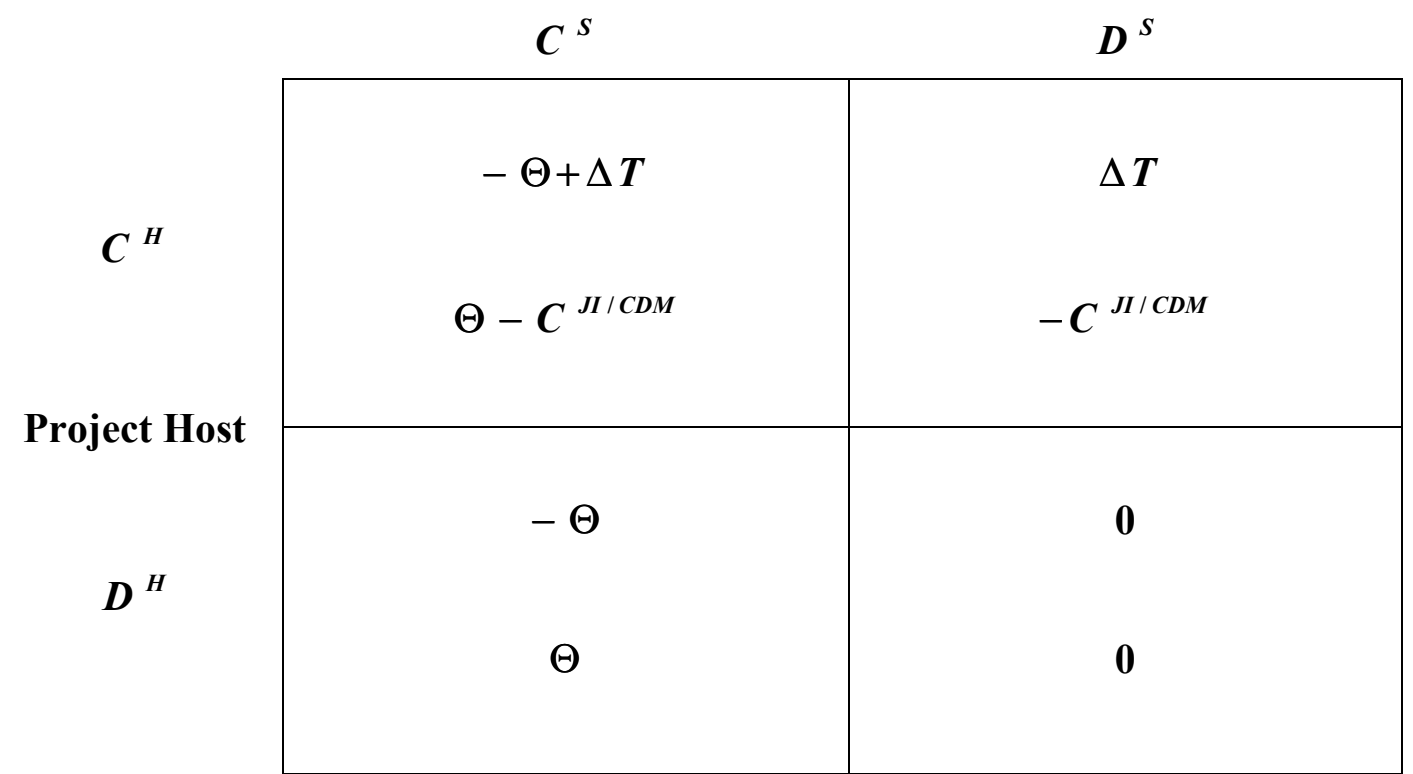

Figure 1: The JI/CDM game

\footnotetext{
${ }^{5}$ In general, the game-theoretic concepts of "action" and "strategy" have two distinct meanings. However, in simultaneous one-shot games they are identical.

${ }^{6} C$ denotes cooperation, whereas $D$ denotes defection.
} 
This game has four different outcomes:

1) The project host and the project sponsor meet their contract obligations. This outcome is the purpose of the contract. The project sponsor provides the agreed funds $\Theta$. The project host adopts the measures necessary to produce additional emission reductions and bears respective incremental implementation costs $C^{J I / C D M}$. The additional emission reductions generated by the project are transferred to the investor who gets credited these emission credits by the national environmental authority towards his domestic emission reduction obligations. For example, these obligations may involve carbon taxes. In this case, the corresponding reduction of the tax base, or carbon tax reimbursement $\Delta T$ represents the return of the JI/CDM investment.

2) Neither the project host, nor the project sponsor abides by the contract. Since the project is not implemented, no incremental costs of the JI/CDM project $C^{J I / C D M}$ arise. The investor does not receive any emission credits because no additional emission reductions are generated. Consequently, he has to pay the full carbon tax, or does not receive any tax reimbursement $\Delta T$.

3) The project host does not abide by the contract, whereas the project sponsor does. This outcome is possible due to the assumption of simultaneous decisions and moves. The investor provides the agreed funds $\Theta$, but does not receive any emission credits. Consequently, besides providing the project funds he is also obliged to pay the full carbon tax, or equivalently, does not receive any tax reimbursement $\Delta T$. Since the host does not implement the project he does not bear any incremental project costs $C^{J I / C D M}$, but obtains the JI/CDM investment funds $\Theta$.

4) The project host meets his contract obligations whereas the project sponsor breaches the contract. In this case, the host implements the JI/CDM project and bears the incremental project costs $C^{J I / C D M}$, but does not receive any investment funds. Supposing that the national environmental authority is 
only interested in the environmental performance of the project, the investor receives the carbon tax reimbursement $\Delta T$, since the project actually has generated additional emission reductions. Possible consequences of a modification of this assumption are discussed in the next section.

How will the players of the game, i.e. the JI/CDM contract parties behave? Or in other words, which outcome represents the equilibrium of the game? In order to answer this question it is necessary to specify the level of the investment payment $\Theta$. For this purpose the two participation constraints are used: Due to liberty of entering into contracts, both parties will sign the contract only if they are better off as compared to noncooperation. This requires in the present case that the following participation constraints need to be met $\left[U^{l}(\right.$.$) denotes the utility of players l, l=H, S$, as a function of the outcome of the game]:

$$
\begin{aligned}
& U^{S}\left(C^{S}, C^{H}\right)=-\Theta+\Delta T \geq 0=U^{S}\left(D^{S}, D^{H}\right) \\
& U^{H}\left(C^{H}, C^{S}\right)=\Theta-C^{J I / C D M} \geq 0=U^{H}\left(D^{H}, D^{S}\right)
\end{aligned}
$$

Designing the contract, rational parties will take into account these individual rationality constraints. Rearranging equation (1) yields:

$$
\Delta T \geq \Theta
$$

This participation constraint of the sponsor requires that the investment payment to the project host should be lower than the carbon tax reimbursement that he will get surrendering to his national environmental authority the emission credits produced.

Rearranging equation (2) yields:

$$
\Theta \geq C^{J I / C D M}
$$


This is the participation constraint of the project host. It requires that the investment payment from the sponsor should at least cover the incremental costs of the JI/CDM project.

Putting together both participation restrictions (3) and (4) makes clear that the investment payment should be in the following interval:

$$
\Delta T \geq \Theta \geq C^{J I / C D M}
$$

Frequently it is assumed that the investment payment equals the incremental costs $\left\lfloor=C^{J I / C D M}\right]$. This, however, is only true if the bargaining or market power is completely with the sponsor such that he can seize the entire efficiency gain. This situation can be considered as rather being an exception. ${ }^{7}$

Having determined the possible range of the investment payment $\Theta$, and applying the concept of Nash equilibrium, it is easy to show that the solution of this noncooperative JI/CDM game is represented by the combination $\left(D^{H}, D^{S}\right){ }^{8}$ In Nash equilibrium, each player's choice is a best response to the strategies actually played by his rivals. In the present case, besides being a Nash equilibrium the solution of this game is in fact an equilibrium in dominant strategies: The sponsor's best strategy is the noncooperative action $\left(D^{S}\right)$ since this yields the highest pay-off independently of the actual choice of the project host. Also the project host's best choice is contract breach $\left(D^{H}\right)$ independently of the sponsor's choice. Since for both players the non-cooperative strategy is the best one, both the host and the sponsor will breach the contract even if contract fulfilment on both sides would increase the individual utility. Hence, the JI/CDM game represents an inefficient prisoner's dilemma.

Central question is now, how to prevent this sub-optimal outcome? At first glance, it seems reasonable to suppose that a modification of the static framework of the inherent long-term relationship between the sponsor and the host may alleviate the cooperation problem: Assuming a repeated interaction between both parties could create an incentive to cooperate since the long-term benefits of meeting the obligations could outweigh the short-

\footnotetext{
${ }^{7}$ See Janssen and Mohr (1998), Mohr (1996), Siniscalco, Goria and Janssen (1998).

${ }^{8}$ Using the concept of Nash equilibrium, the possibility of renegotiations is neglected. Hence, renegotiation stability [Farrell and Maskin (1989) or Van Damme (1989)] is not considered.
} 
term benefit of breaching the contract. Both players could base their future behaviour on the observed past behaviour of the rival.

Unfortunately, this supposition is wrong. If both players have a finite time horizon and complete information, and if the Nash equilibrium of the simultaneous one-shot game is unique, then repeated interaction will not change non-cooperative behaviour into cooperative behaviour. The reason for this basic result of game theory may be illustrated by backward induction: In the last round of a finitely repeated game, both players have an incentive to defect, independently of each other's previous behaviour. In the last but one round, cooperation is only attractive if rewarded by cooperation in the next round. But, since in the last round both players in any case behave non-cooperatively, rewarding of cooperative behaviour in the last but one round is not possible. For this reason, no party will behave cooperatively in the last but one round. This argumentation may be carried on up to the first round.

Based on this analysis, the question arises if cooperation problems associated with international JI/CDM projects will inevitably lead to unstable JI/CDM regimes? This question will be addressed in the next section.

\section{Institutions and Strategies for Stabilising JI and CDM Contracts}

In the previous section the basic problem of breach of international JI/CDM contracts has been exposed. The solution of this problem is essential for the implementation of an effective and efficient JI/CDM regime. The purpose of this section is to analyse possible institutions and strategies for stabilising JI/CDM contracts.

In the case of non-binding contracts, cooperative behaviour of the parties may be generated by an incentive-compatible contract design. In general, an incentive-compatible contract design comprises specific rules regarding the fulfilment of the contract obligations. Such specific rules may be interpreted as institutional elements of international JI/CDM contracts. This interpretation of institutions is based on the following definition (North, 1994, p. 360): 
Institutions are the humanly devised constraints that structure human interaction. They are made up of formal constraints (e.g. rules, laws, constitutions), informal constraints (e.g., norms of behaviour, conventions, self-imposed codes of conduct), and their enforcement characteristics.

In this sense, the present section analyses aspects of the institutional design required for the successful implementation of JI/CDM projects.

\subsection{Commitment of the Sponsor by Advanced Payment}

The basic problem of the JI/CDM game analysed in the previous section is the inability of both contract parties to credibly commit to cooperative behaviour. The resulting instability and inefficiency of the JI/CDM contract, i.e. the breach of contract on both sides, can be removed if both parties can adopt mechanisms for a credible commitment.

A first step in this direction may consist in deferred or sequential fulfilment of the contract obligations. In this case, the first-moving player becomes a Stackelberg leader. This constitutes a credible commitment because the second player, i.e. the Stackelberg follower, can base his own behaviour on the observable behaviour of the Stackelberg leader. If the later does not comply, the former too has the possibility to behave noncooperatively.

This sequential fulfilment of contract obligations makes it possible for the Stackelberg leader to commit credibly, since his behaviour is observable. However, the second player is still faced with the problem of credible commitment. Obviously, the first player is not willing to become the Stackelberg leader if the second player is not successful in adopting a mechanism for credibly committing himself. Hence, the development of a commitment mechanism for the second player is a precondition for the first player becoming a Stackelberg leader. This issue will be dealt with in the next subsection.

Another problem refers to the question who of the two parties should become the leader and who the follower? In the present case, the temporal sequencing of action doesn't 
seem to be predetermined by a "natural" structure. ${ }^{9}$ In principle, both parties could move first, leaving the task of developing a commitment mechanism to the other side. In the following it is assumed that the project sponsor is moving first, becoming the Stackelberg leader. Hence, the focus of the next subsection's analysis is on mechanisms by which the project host can commit himself in a credible manner. It should be emphasised, however, that also the reverse structure is possible and plausible.

\subsection{Commitment Strategies of the Project Host}

In this subsection possible mechanisms for a credible commitment of the project host are analysed. Following strategies are discussed: On the one hand, the paper explores the possible role of the national environmental authority of the host's country in facilitating credible commitment of the project host. On the other hand, it is examined if the host could achieve a credible commitment delegating strategically the implementation of the project to an agent.

\subsubsection{Punishment of Breaches of Contract by the National Environmental Authority}

Until now it has been implicitly assumed that the national environmental agency in the host country serves only the following functions:

- Verification if the JI/CDM project actually generates additional emission reductions.

- If the result of verification is positive, transfer of the emission credits obtained to the investor and corresponding registration of the transfer on the national account of greenhouse gas emissions.

\footnotetext{
${ }^{9}$ This is e.g. the case considering the supply decision of a monopolist as a Stackelberg game: The monopolist moves first fixing the profit-maximising supply price by taking into account the reaction function of the rival "demand side", i.e. the demand function. Afterwards the Stackelberg follower, i.e. the demand side, decides about the optimal demand quantity.
} 
National environmental authorities may play an additional role concerning the implementation of successful JI/CDM projects: By means of establishing an appropriate mechanisms by which possible breaches of contract by the project host are punished, the national environmental authority may facilitate a credible commitment of the project host.

What is an appropriate punishment mechanism? The previous discussion made clear that the project host is unable to commit himself in a credible manner since noncooperative behaviour makes him better off independently of the sponsor's behaviour. This problem can be removed if the national environmental authority imposes a punishment on the project host in case of non-cooperative behaviour. The level of this punishment $\Psi$ should be fixed at a level that allows the host to signal a credible commitment. In this case, the project sponsor rightly assumes that the project host will abide by the contract. Hence, he is willing to move first behaving cooperatively.

The appropriate level of punishment $\Psi$ may be easily determined by the pay off matrix of the JI/CDM game (see figure 1): If the project sponsor behaves cooperatively, a breach of contract on the part of the project host is (strictly) disadvantageous as compared to cooperative behaviour, if the following condition is met:

$$
U^{H}\left(C^{H}, C^{S}\right)=\Theta-C^{J I / C D M}>\Theta-\Psi=\bar{U}^{H}\left(D^{H}, C^{S}\right)
$$

$\bar{U}^{H}\left(D^{H}, C^{S}\right)$ denotes the host's utility level in the situation in which the sponsor complies, but the host doesn't and consequently gets punished by the national environmental authority. Rearranging equation (6) yields:

$$
\Psi>C^{J I / C D M}
$$

This condition requires that the national environmental authority should fix the punishment at a level which is higher that the incremental costs of the project. However, since the incremental costs of the JI/CDM project are not directly observable, and since the host may have an incentive not to reveal this strategically important variable, the national environmental authority may have some problems to fix the punishment at a level, which is effective and credible. However, since the incremental costs are in any case lower than the monetary value of the emission credits produced, i.e. the corresponding carbon tax 
reimbursement $\Delta T$ to the project sponsor [see condition (5)], and since this variable is easily observable, an effective punishment could be fixed at the level

$$
\Psi=\Delta T
$$

This punishment rule is indeed incentive-compatible as the following summary of the entire mechanisms makes clear:

1) Greenhouse gas emitting companies faced with some kind of reduction obligation may invest in JI/CDM projects and credit resulting additional emission reductions towards their domestic reduction obligations, e.g. a carbon tax. The governments of the sponsor and host country have signed a respective cooperation agreement.

2) Besides usual monitoring, accounting and reporting functions, the national environmental authority of the host country develops the rule that project hosts who do not comply with the obligations as stipulated by the JI/CDM contract have to pay a punishment which equals the missed tax reimbursement on the part of the project sponsor. All JI/CDM investors know this rule.

3) The project host and the project sponsor agree the terms of the JI/CDM contract.

4) The project sponsor transfers the investment funds as stipulated by the contract.

5) The project host verifies receipt of respective investment funds and implements the measures required to generate additional emission reductions. If the sponsor had not transferred the agreed investment funds, the project host would not have started to implement the project.

6) If the project host would refrain from implementing the project, he would be forced by the national environmental authority to pay a punishment equal to the monetary value of the planned emission credits.

7) Due to incentive-compatibility of this mechanism, both parties abide by the contract obligations. 
The incentive-compatibility of this arrangement can easily be shown: The project host, which moves last, has no incentive to behave non-cooperatively, since in this case he would be forced by the national environmental authority to pay a penalty which makes it disadvantageous to breach the contract [see conditions (8), (5) and (6)]. Due to this mechanism, the project sponsor will rightly assume cooperative behaviour on the part of the host. He abides by the contract, since otherwise the host would refrain from implementing the project, and the sponsor would not receive any emission credits being obliged to pay the higher carbon tax.

\subsubsection{Self-Commitment of the Project Host through Strategic Delegation}

The fundamental reason of the instability of the JI/CDM contract as analysed in section 2 is based on the fact that international contracts de facto are difficult to enforce. On the contrary, contracts at the national level are enforceable by sovereign authorities. For this reason it is appealing to ask the question if a credible commitment towards a foreign party could be achieved by making a contract with a third party at the national level.

More generally, this question may be put as follows: Is it possible to implement the cooperative outcome of a non-cooperative game by allowing one or both players to enter into binding contracts with a third or fourth party $?^{10}$ This question has been analysed in recent years within different contexts under the heading "strategic delegation". ${ }^{11}$ In the following, the basic idea of strategic delegation will be applied to the question, if the project host may be able to commit himself credibly with respect to his international obligations using strategic delegation. This question will be of importance if the mechanism discussed in the previous subsection is not functioning effectively for some reason or another.

\footnotetext{
${ }^{10}$ Schelling (1956) and (1960) has advanced this possibility.

${ }^{11}$ Strategic delegation has been analysed e.g. in the following contexts: Interrelation between shareholders and managers in oligopoly markets [Vickers (1985)], industrial economics [Caillaud and Rey (1995)], time inconsistency of monetary policy [Walsh (1995)], international coordination of national monetary policies [Dolado, Griffith and Padilla (1994) and Persson and Tabellini (1995)]. A general analysis of strategic delegation is Fershtman, Judd and Kalai (1991).
} 
The basic idea of strategic delegation consists in the following: The player exposed to credibility problems entitles another player to play the game on his behalf. The entitling player becomes a principal, whereas the entitled player becomes the agent of the new game. The contract between the principal and the agent has to be designed in such a way that the agent is better off by playing the cooperative strategy in the original game than choosing the non-cooperative strategy. If the second player of the original game has complete information about the principal-agent contract then the original credibility problem of the principal may be mitigated.

How might these considerations be applied to the JI/CDM game in consideration? How should the principal-agent contract be designed in order to ensure a credible commitment of the project host?

In a first step, the project host and the agent agree on the terms of the contract. The agent agrees to implement the contract on behalf of the host. Having implemented the $\mathrm{JI} / \mathrm{CDM}$ project he receives a payment for serving as an agent which should depend on the gross pay off of the principal, i.e. the pay off net of the payment to the agent. This relation between agent and principal is fixed by a contract, which is binding, by assumption. For this reason the agent can be sure to receive his payment after having implemented the JI/CDM project.

The central question of this strategic delegation is how to design the principalagent contract in such a way that the agent does not have any incentive to behave noncooperatively with respect to the original JI/CDM game. Just as an example it might be assumed that the payment to the agent is a positive linear function of the project host's gross pay off. This structure, however, is not incentive-compatible: As already explained above, the project host's best strategy is to behave non-cooperatively, since in this case he gets a higher payoff. If the payment to the agent is a positive linear function of the principal's pay off, also the agent's best strategy is to behave non-cooperatively in the JI/CDM game.

An incentive-compatible principle-agent contract should rather fix the following payment $\Omega\left(U^{H}\right)$ to the agent: ${ }^{12}$

\footnotetext{
${ }^{12}$ If $\Omega^{*}=\Omega^{* *}$, the agent is indifferent between cooperative and non-cooperative behaviour in the original $\mathrm{JI} / \mathrm{CDM}$ game. In this case, the equilibrium would not be unique. Based on the idea of focal points [Schelling (1960)] one could argue that the cooperative behaviour would prevail, however.
} 


$$
\Omega\left(U^{H}\right)=\left\{\begin{array}{l}
\Omega^{*} \text { if } \quad U^{H}=U^{H}\left(D^{H}, C^{S}\right) \\
\Omega^{* *} \text { if } \quad U^{H}=U^{H}\left(C^{H}, C^{S}\right)
\end{array} ; \text { with } \Omega^{* *}>\Omega^{*} \geq 0\right.
$$

This principal-agent contract meets the agent's participation constraint due to $\Omega^{* *}>\Omega^{*} \geq 0 .{ }^{13}$ The principal's participation constraint is met if

$$
U^{H}\left(C^{H}, C^{S}\right)-U^{H}\left(D^{H}, D^{S}\right) \geq \Omega^{* *}
$$

This condition requires that the host's pay off in the cooperative outcome of the JI/CDM game net of the payment to the agent must be higher than his pay off in the noncooperative outcome. ${ }^{14}$ If the agent would pretend a higher payment, the principal would not benefit from the strategic delegation.

The entire structure of the proposed mechanism of delegating the JI/CDM project implementation strategically may be summarised as follows:

a) The project host and his agent make a binding contract regarding the implementation of the yet to be agreed JI/CDM contract. All potential project sponsors know the contract.

b) The project sponsor and the project host agree on the terms of the JI/CDM contract.

c) The project sponsor transfers the investment funds $\Theta$ to the project host.

d) The project host pays his agent the incremental costs of the project implementation.

e) After having implemented the project, the agent receives his payment $\Omega^{* *}$.

f) The emission credits generated are transferred to the sponsor who surrenders them to the national environmental authority in order to get the carbon tax reimbursement.

\footnotetext{
${ }^{13}$ With this specification it is assumed that the reservation utility of the agent is normalised to zero. The reservation utility represents the utility level of the next best opportunity available to the agent.

${ }^{14}$ The relative bargaining power of the agent and the principal determines the precise level of the payment to the agent within these two participation constraints of the principal-agent contract.
} 
This structure of both the JI/CDM contract and the principal-agent contract ensures a credible commitment of the project host and the project sponsor. Both, the $\mathrm{JI} / \mathrm{CDM}$ contract and the principal-agent contract are beneficial to all parties involved since all parties are able to share in the efficiency gains produced by the implementation of the $\mathrm{JI} / \mathrm{CDM}$ project considered.

The net benefits resulting from the effective project implementation for the individual parties are specified as follows:

JI/CDM project sponsor:

$$
-\Theta+\Delta T>0
$$

JI/CDM project host:

$$
\Theta-C^{J I / C D M}-\Omega^{* *}>0
$$

Agent of the JI/CDM host:

$$
\Omega^{* *}>0
$$

All parties share in the efficiency gains produced by the implementation of the JI/CDM project considered.

\section{Outlook}

International JI and CDM projects may significantly contribute to the costefficient achievement of the emission reduction and limitation targets stipulated by the Kyoto protocol. However, enforcement problems associated with international contracts due to state sovereignty may lead to unstable JI and CDM contracts and ultimately prevent the realisation of potential efficiency gains. 
This paper has analysed this problem adopting a game-theoretic approach. Two different possible solutions have been proposed, involving sequential moving of contract parties, punishment by national environmental authorities and strategic delegation.

Further research into the issues dealt with may cover the following question. Is it conceivable that the punishment mechanism proposed in this paper might be burdened with credibility problems of the national environmental authority? Which strategies do exist to remove this conceivable credibility problem? What are further strategies other than those proposed in this paper available for removing inherent enforcement problems of international JI and CDM contracts? What are the potentials of cross-default contracts successfully employed in the field of international debt relations in mitigating enforcement problems of international climate protection cooperation $?^{15}$

\footnotetext{
${ }^{15}$ Regarding the concept of cross-default arrangements and its application to international environmental cooperation see Mohr (1995) and Mohr and Thomas (1998).
} 


\section{References}

BARRET, S. (1994): „Self-Enforcing International Environmental Agreements“, Oxford Economic Papers 46, 878-894.

Caillaud, B. and P. Rey (1995): „Strategic Aspects of Delegation“, European Economic Review 39, 421-431.

Carraro, C. and D. SinisCalco (1993): „Strategies for the International Protection of the Environment“", Journal of Public Economics 52, 309-328.

Dolado, J., Griffith, M. and A. J. Padilla (1994): „Delegation in International Monetary Games“, European Economic Review 38, 1057-1069.

EAton, J. and R. Fernandez (1995): „Sovereign Debt“, in: Grossman and RogofF (eds.), 2031-2077.

FARRELL, J. and E. MASKIn (1989): „Renegotiation in Repeated Games“, Games and Economic Behaviour 1, 327-360.

Fershtman, C., JudD, K. L. and E. Kalai (1991): „Observable Contracts: Strategic Delegation and Cooperation“, International Economic Review 32, 551-559.

GoldemberG, J. (ed.) (1998): Issues \& Options: The Clean Development Mechanism, United Nations Development Programme: New York.

Grossman, G. and K. RogofF (eds.) (1995): Handbook of International Economics Volume III, Elsevier: Amsterdam.

Heister, J. et al. (1997): „Strategies to Enforce Compliance with an International CO2International Environmental Affairs 9, 22-53.

JANSSEN, J. and E. MoHR (1998): „The Window of Opportunity for Rain Forest Protection: The Time Remaining in the Rio-Process“, International Environmental Affairs 10, 40-63. 
JEPMA, C. J. (ed.) (1995): The Feasibility of Joint Implementation, Kluwer Academic Publishers: Dordrecht.

MAtsuO, N. (1998): „Key Elements Related to the Emissions Trading for the Kyoto Energy Policy 26, 263-273.

MisSFELDT, F. (1998): „Flexibility Mechanisms: Which Path to Take after Kyoto?“, Review of European Community and International Environmental Law 7, 128-139.

MOHR, E. (1996): „Sustainable Development and International Distribution: Theory and Review of International Economics 4, 152-171.

MoHR, E. (1995): „International Environmental Permit Trade and Debt: the Consequences of Country Sovereignty and Cross-Default Policies“, Review of International Economics 3, 1-19.

MoHr, E. (1991a): Economic Theory and Sovereign International Debt, Academic Press: London.

MoHr, E. (1991b): „Global Warming: Economic Policy in the Face of Positive and Negative Spillovers“, in: SIEBERT (ed.), 187-211.

Mohr, E. and J. Thomas (1998): „Pooling Sovereign Risks: the Case of Environmental Treaties and International Debt“", Journal of Development Economics 55, 153-169.

NorTh, D. C. (1994): „Economic Performance through Time“, American Economic Review 84, 359-368.

Persson, T. and G. TAbellini (1995): „Double-Edged Incentives: Institutions and Policy Coordination“, in: Grossman and RogOFF (eds.), 1973-2030.

Schelling, T. C. (1960): The Strategy of Conflict, Oxford University Press: Oxford.

Schelling, T. C. (1956): „An Essay on Bargaining“, American Economic Review 46, 281-306. 
SCHмIDT, C. (1998): Incentives for International Environmental Cooperation: Theoretic Models and Economic Instruments, Nota di Lavoro 56.98, Fondazione ENI Enrico Mattei FEEM: Milan.

SCHRIJVER, N. (1995): „Joint Implementation from an International Law Perspective“, in: JEPMA (ed.), 133-141.

SIEBERT, H. (1991) (ed.): Environmental Scarcity: the International Dimension, Mohr: Tübingen.

Siniscalco, D., Goria, A. and J. JansSen (1998): „Outstanding Issues“, in: Goldemberg (ed.), 91-98.

STAIGER, R. W. (1995): „International Rules and Institutions for Trade Policy“, in: GROSSMAN and ROGOFF (eds.), 1495-1551.

Thomas, J. and T. Worrall (1994): „Foreign Direct Investment and the Risk of Review of Economic Studies 61, 81-108.

UNFCCC (1998): Matters Related to the Kyoto Protocol: Work Programme on Mechanisms, United Nations Framework Convention on Climate Change, FCCC/CP/1998/L.21.

VAN DAMme, E. (1989): „Renegiotiation-Proof Equilibria in Repeated Prisoners' Journal of Economic Theory 47, 206-217.

VICKERS, J. (1985): „Delegation and the Theory of the Firm“, Economic Journal (Supplement) 95, 138-147.

WALSH, C. (1995): „Optimal Contracts for Central Bankers“, American Economic Review $85,150-167$. 